\title{
CD14CD16 monocyte subset levels in heart failure patients
}

\author{
Chiara Barisione ${ }^{\mathrm{a}, 1}$, Silvano Garibaldi ${ }^{\mathrm{a}, 1}$, Giorgio Ghigliotti ${ }^{\mathrm{a}, *}$, Patrizia Fabbi $^{\mathrm{a}}$, Paola Altieri ${ }^{\mathrm{a}}$, \\ Maria Carla Casale $^{\mathrm{a}}$, Paolo Spallarossa ${ }^{\mathrm{a}}$, Giovanni Bertero ${ }^{\mathrm{a}}$, Manrico Balbi ${ }^{\mathrm{a}}$, Luca Corsiglia ${ }^{\mathrm{b}}$ and \\ Claudio Brunelli ${ }^{\mathrm{a}}$ \\ ${ }^{a}$ Division of Cardiology, Department of Internal Medicine, Research Center of Cardiovascular Biology, University \\ of Genova, V.le Benedetto XV, 616132 Genova, Italy \\ ${ }^{\mathrm{b}}$ Casa Di Cura Istituto Cardiovascolare Camogli (ISC), Camogli, Italy
}

\begin{abstract}
Our aim was to define the distribution of monocyte subsets in a cohort of congestive heart failure (CHF) patients, to verify whether increased severity of $\mathrm{CHF}$ is linked to the expansion of specific monocyte subsets, and finally to investigate the relationship between monocyte subset relative frequencies, laboratory parameters of inflammation, and monocyte ACE expression.

Thirty consecutive CHF patients and 26 healthy control subjects were evaluated for peripheral blood monocyte expression of CD14, CD16 and CD143 (ACE) by flow-cytometry, and for endothelial-derived soluble CD146 levels by ELISA.

$\mathrm{CD} 14^{++} \mathrm{CD}_{16}{ }^{+}$frequency was significantly higher in CHF patients than in Controls (\%, median value and IQ) $(12.3,8.7-14.8$ vs 5.9, 4.7-6.9, $p<0.05$, CHF vs Controls), and it increased depending on how high NYHA class was, on worsening LV ejection fraction and on circulating pro-BNP values. Furthermore, it was associated with increasing creatinine and with decreasing GFR and albumin levels. Monocyte CD143 expression was significantly elevated in CHF patients as compared to Controls, and positively associated with $\mathrm{CD} 14^{++} \mathrm{CD} 16^{+}$levels. Frequencies of $\mathrm{CD} 14^{+} \mathrm{CD} 16^{+}$monocytes were significantly lower in $\mathrm{CHF}$ patients as compared to Controls, and negatively correlated with levels of soluble CD146 ( $r=-0.529$; p 0.048).

In conclusion, monocytic $\mathrm{CD} 14^{++} \mathrm{CD} 16^{+}$frequency and $\mathrm{CD} 143$ levels are increased and reflect disease status and progressive cardiac deterioration in $\mathrm{CHF}$ patients. The $\mathrm{CD} 14^{+} \mathrm{CD} 16^{+}$subset is depleted in $\mathrm{CHF}$ and is linked to endothelial damage in this group of patients.

Although the question of whether differences in monocyte CD14CD16 expansion are causal or whether they represent a marker of HF progression which is potentially relevant for risk prediction remains unanswered, we believe that our data represent an important tool for exploring the role of selective inflammatory pathways in CHF progression.
\end{abstract}

Keywords: Angiotensin, congestive heart failure, monocytes, peptidyl-dipeptidase A, antigens, CD14, receptors, IgG, kidney failure, chronic

\section{Introduction}

Congestive heart failure is a malignant condition with sharp upturn in both prevalence and incidence and

\footnotetext{
*Corresponding author: Giorgio Ghigliotti MD, Research Associate of Cardiology Department of Internal Medicine, Cardiology, University of Genova, Viale Benedetto XV, 616132 Genova, Italy. Tel.: +39 010 3537922; Fax: +39 010353 8655; E-mail: gghiglio@ unige.it.

${ }^{1}$ These two authors contributed equally to the study.
}

with high rates of morbidity and mortality [1]. CHF patients represent disabled patients with chronic cardiovascular disease who use health care resources [2]. Poor prognosis suggests that important pathogenic mechanisms remain active and unmodified by current treatment regimens. Recent data suggest a role for inflammatory and immunological processes in the pathogenesis and progression of CHF [3]. Increased levels of pro-inflammatory cytokines are related to increased rates of mortality in $\mathrm{CHF}$ patients. Monocytes play a key role in a variety of pathophysiological process- 
es in cardiovascular biology. Heterogeneity in phenotype and function has been observed among human monocytes. Different expressions for CD14 (part of the receptor for the lipopolysaccharide) and CD 16 (Fcgamma receptor III) have been used to define two major subsets in the peripheral blood. One includes the majority of monocytes, defined as classical monocytes $\left(\mathrm{CD} 14^{++} \mathrm{CD}^{-} 6^{-}\right)$, acting as scavengers toward apoptotic cells and aiding in the resolution of inflammation, whereas a minor subset, known as $\mathrm{CD} 14^{+} \mathrm{CD}_{16}{ }^{+}$, expresses pro-inflammatory cytokines such as TNFalpha, and has the ability to respond directly with antimicrobial activity. Nockher initially reported that the subset of monocytes expressing CD16 ${ }^{+}$together with low levels of $\mathrm{CD}_{14}{ }^{+}$was expanded in dialysis patients [4]. It has recently been shown that CD16 ${ }^{+}$ monocytes are further differentiated by phenotype into $\mathrm{CD} 14^{++} \mathrm{CD} 16^{+}$and $\mathrm{CD} 14^{+} \mathrm{CD} 16^{+}$monocytes, and that they also differ with regards to the type of cytokines that are secreted [5]. Vascular cell-bound angiotensin converting enzyme (ACE), detected as CD 143, is present at high levels on monocytes, [6] and increases during monocyte-macrophage-dendritic cell differentiation [7]. Monocytic ACE expression has been linked to increased $\mathrm{CD} 14^{++} \mathrm{CD} 16^{+}$levels in dialysis patients with cardiovascular disease [8]. The $\mathrm{CD} 14^{++} \mathrm{CD} 16^{+}$ subset of the peripheral blood monocyte population, which is estimated to be a minor monocyte subpopulation in healthy individuals $(8 \%-10 \%)$, expands in chronic inflammatory disorders, such as rheumatoid arthritis, [9] inflammatory bowel disease, [10] and severe asthma [11]. This monocyte subset produces large amounts of pro-inflammatory cytokines, such as interleukin(IL)-1, and may act in concert with activated peripheral blood multi-nuclear cells, circulating chemokines, and cytokines, thus provoking cardiac and extracardiac damage. Chronic low grade inflammation has been demonstrated at different stages of heart failure, consistent with the broader profile and systemic nature of the damage in CHF patients [12]. There are currently no available studies describing a pattern of monocyte subsets in CHF patients. The aims of our work were: to determine the distribution of monocyte subsets in CHF patients, to verify whether increased severity of $\mathrm{CHF}$ is linked to expansion of specific monocyte subsets, and finally to investigate the relationship between monocyte subset relative frequencies, laboratory parameters of inflammation, and monocyte ACE expression.

\section{Materials and methods}

\subsection{Study population}

We selected thirty consecutive male patients from the congestive heart failure outpatient clinic of the S. Martino University Hospital, Genova and 26 healthy male control subjects. All study patients gave informed consent in advance for their participation; the research protocol conformed with the principles outlined in the declaration of Helsinki, and the ethics committee at our institution approved the protocol. Stable patients with CHF class I/II/III (New York Heart Association classification) were taken into consideration for inclusion into our study. Eligibility criteria of CHF patients for this study included: CHF lasting longer than 12 months, diagnosis according to the Framingham criteria, [13] clinical stability and administration of the same medical regimen for at least three weeks prior to study entry. CHF was diagnosed when patients with clinical heart failure had an ejection fraction of $\leqslant 45 \%$ by 2-dimensional transthoracic echocardiography. Heart failure severity was assessed according to the NYHA classification. The aetiology for $\mathrm{CHF}$ was ischemic heart disease in seventeen $(57 \%)$ (11 patients with previous MI, 6 patients with coronary artery disease defined by the presence of at least one coronary stenosis [ $>70 \%$ ] detected at coronary angiography) and idiopathic dilated cardiomyopathy in thirteen $(43 \%)$. The cohort of control subjects were recruited from our outpatient cardiac service, and included healthy subjects with one or more major modifiable cardiovascular risk factors. They were screened for the absence of organic heart disease by history, physical examination, 12-lead electrocardiography and 2-dimensional transthoracic echocardiography. Cardiovascular disease risk factors were assessed by giving standardized interviews to all patients and controls. Since CHF patients represent an aged subgroup of patients in whom renal damage is frequently present, our study included both patients with preserved (stage 1) kidney function and patients with mild-to-moderate (stage 2 and 3) chronic kidney disease (CKD), as defined by estimated glomerular filtration rate (GFR) in $\mathrm{ml} / \mathrm{min} / 1.73 \mathrm{~m}^{2}$ body surface area. Patients with significant concomitant diseases such as infections, osteoarthritis, cancer, autoimmune disease, malnutrition (serum albumin $<2.0 \mathrm{~g} / \mathrm{dl}$ ), inflammatory bowel disease, chronic liver disease or GFR below $45 \mathrm{ml} / \mathrm{min} / 1.73 \mathrm{~m}^{2}$ body surface area were excluded. 


\subsection{Laboratory methods}

Fasting blood samples were collected from all study subjects on the morning of their outpatient clinical appointment, after resting in the supine position for 20 minutes. Serum fibrinogen, blood count, plasma glucose, lipid, liver and renal profile, total protein, albumin, $\mathrm{C}$-reactive protein (CRP), and N-terminal probrain natriuretic peptide (pro-BNP) were obtained using standard techniques. Baseline GFR was estimated using the four-variable Modification of Diet in Renal Disease formula [14]. Leukocyte and monocyte counts were measured using automated cell counters by standard techniques. Blood was withdrawn from an antecubital vein and then centrifuged at $1710 \mathrm{~g}$ for 15 minutes at $4^{\circ} \mathrm{C}$. Immediately after centrifugation, serum samples were stored at $-80^{\circ} \mathrm{C}$ until they were assayed. Plasma levels of the soluble form of the endothelial cell-cell adhesion molecule CD146 (sCD146, BioCytex, France) was measured by ELISA according to the manufacturer's recommendations.

\subsection{Monocyte subset analysis}

Monocyte subpopulations were analyzed by flow cytometry. Mononuclear cells were isolated from the blood by density gradient centrifugation over Ficoll, and were immunostained for 15 minutes at room temperature in the dark with the following monoclonal antibodies: $10 \mu \mathrm{l}$ of anti-CD143-FITC antibody (clone 9B9, GeneTex, Inc.), $20 \mu \mathrm{l}$ of anti-CD14 PE antibody (clone RMO52; Beckman Coulter), $20 \mu$ of anti-CD16 PE-Cy5 (clone 3G8; Biolegend). After centrifugation, cells were washed twice with phosphate-buffered saline (PBS) containing $0.1 \%$ bovine serum albumin, $1 \mathrm{mM}$ $\mathrm{CaCl}_{2}$ and $\mathrm{MgCl}_{2}$, and then resuspended in $500 \mu \mathrm{l}$ of PBS containing 2\% paraformaldehyde.

Flow cytometry was performed with the use of a Coulter EPICS XL flow cytometer (Beckman Coulter S.p.A., Milan, Italy). Analysis of data was performed on a personal computer using the WinMDI 2.8 system provided by J. Trotter (Scripps Research Institute, La Jolla, CA, USA). Monocytes were gated on the basis of both morphological and SSC/CD14 dotplots: all CD14 positive cells were included, while cells with granulocyte scatter properties were excluded. Monocyte subsets $\mathrm{CD} 14^{++} \mathrm{CD} 16^{-}, \mathrm{CD} 14^{++} \mathrm{CD} 16^{+}$, and $\mathrm{CD} 14^{+} \mathrm{CD} 16^{+}$were defined according to the surface expression pattern of the lipopolysaccharide receptor CD14 and the Fc-gamma receptor CD16 (see Fig. 1 for a representative example of the analysis procedure).

\subsection{Statistical analysis}

Data are expressed as mean \pm SE. Categorical variables are presented as percentage of study subjects and compared by Fisher's exact test. All variables with a skewed distribution (i.e. CD14CD16 monocyte subsets, fibrinogen, triglycerides) were log transformed to normalize the distribution before statistical analysis. Logarithmically transformed data are presented as median (including the first and third quartiles). Twosided t tests were used in the comparison of normally distributed continuous variables, while non parametric tests (Kruskal Wallis test, Mann Whitney test) were used for non-Gaussian data. Spearman's rank correlation test was used for correlations between variables. A value of $p<0.05$ was considered statistically significant. Data were analyzed in the study subjects as a whole, and then separately in CHF patients and in Control subjects. Since we were mainly and initially interested in evaluating differences between levels of the $\mathrm{CD} 14^{++} \mathrm{CD} 16^{+}$monocyte subset in HF patients and in Controls, and because our data and assessments were exploratory, no adjustments were made for multiple statistical comparisons. We used the data (levels of $\mathrm{CD} 14^{++} \mathrm{CD} 16^{+}$monocyte subset: mean and standard deviation) that we obtained from our 26 Control subjects to calculate power of the study. We set the alpha level (Type I error) to 0.02 (two-tailed), and we set the beta level (Type II error) to 0.20. Expecting we would detect a $25 \%$ change in mean values of $\mathrm{CHF}$ subjects, we came up with a sample of at least $26 \mathrm{CHF}$ patients (four more patients were included in the group of HF patients, thus bringing this group to a total of 30 subjects).

\section{Results}

Baseline characteristics in the two study groups are shown in Tables 1 and 2. No significant differences with regards to personal history of hypertension, dyslipidemia and smoking habit were present between the two study groups. CHF patients showed higher levels of CRP, fibrinogen, and total number of WBC than the Controls. As expected, CHF patients had a higher prevalence of prescription use of digoxin, loop diuretics and beta-blocking agents [15]. At the time of the visit, $40 \%$ of CHF patients exhibited atrial fibrillation and $43 \%$ were in NYHA class III. 
Table 1

Demographics and medical history of the study subjects

\begin{tabular}{lccc}
\hline & CHF patients (30) & Controls (26) & $\mathrm{p}$ \\
\hline Age (years) & $70.9 \pm 2.1$ & $69.5 \pm 2.2$ & $\mathrm{NS}$ \\
Heart rate (bpm) & $71.1 \pm 2.6$ & $70.7 \pm 4.9$ & $\mathrm{NS}$ \\
Ejection fraction (\%) & $29.5 \pm 1.6$ & $60.4 \pm 0.7$ & $<0.001$ \\
Previous myocardial infarction (\%) & $37 \%$ & 0 & - \\
Hx of chronic atrial fibrillation (\%) & $40 \%$ & 0 & - \\
Hx of previous smoke (\%) & $87 \%$ & 88 & $\mathrm{NS}$ \\
Hx of hypertension (\%) & $80 \%$ & 81 & $\mathrm{NS}$ \\
Hx of hypercholesterolemia (\%) & $63 \%$ & $58 \%$ & $\mathrm{NS}$ \\
Concomitant treatment & & & \\
Digoxin (\%) & $23 \%$ & $0 \%$ & - \\
Angiotensin-converting enzyme inhibitors (\%) & $63 \%$ & $50 \%$ & $\mathrm{NS}$ \\
Loop diuretics (\%) & $70 \%$ & $0 \%$ & - \\
Spironolactone (\%) & $50 \%$ & $0 \%$ & - \\
$\beta$-blockers (\%) & $77 \%$ & $31 \%$ & $<0.005$ \\
Aspirin (\%) & $63 \%$ & $50 \%$ & $\mathrm{NS}$ \\
Oral or subcutaneous anticoagulant (\%) & $50 \%$ & $0 \%$ & - \\
Lipid lowering drugs (\%) & $27 \%$ & $31 \%$ & $\mathrm{NS}$ \\
\hline
\end{tabular}

Values are expressed as mean $( \pm \mathrm{SE})$, median $(\mathrm{IQ})$, or as percentage. $\mathrm{CHF}=$ Congestive Heart Failure. $-=$ not estimated.
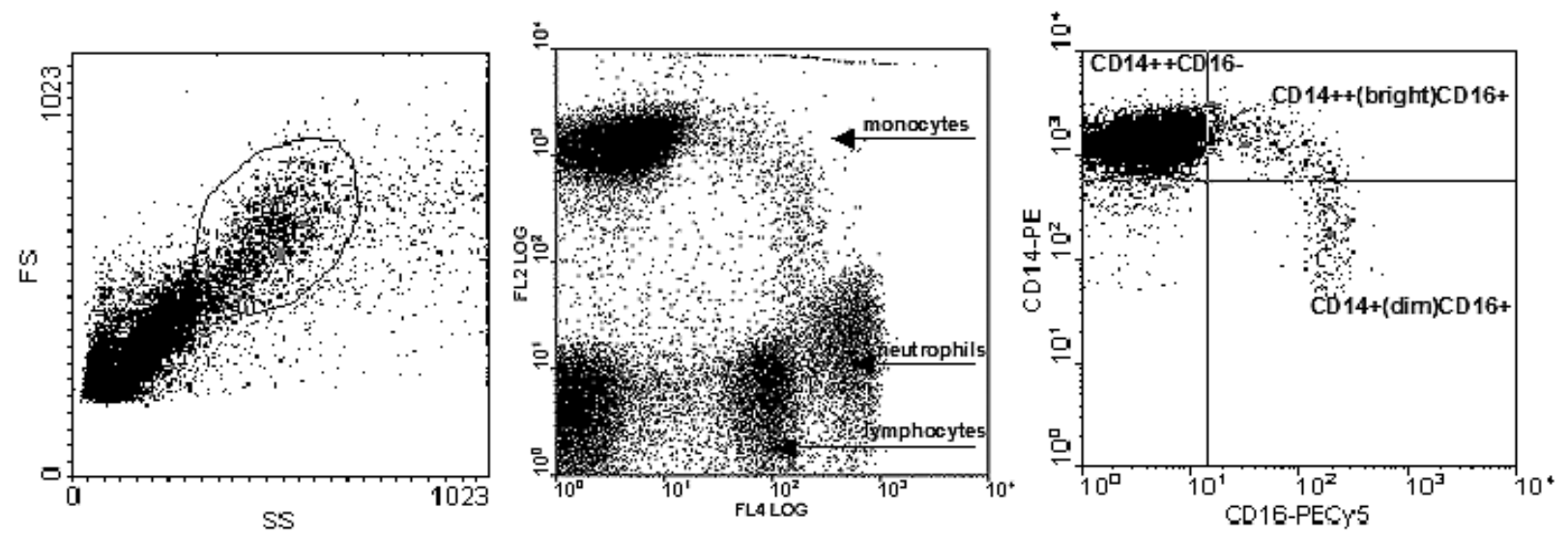

Fig. 1. Flow cytometric dot plots depicting representative analysis for the identification of monocyte subsets. Left panel) morphological (side scatter, SSC and forward scatter, FSC) dot plot of cells with total monocyte gating; middle panel) CD14 (FL-2), CD16 (FL-4) fluorescence ungated dot plot showing all white blood cell populations; right panel) gated dot plot showing the distribution of CD14 and CD16 on peripheral blood monocytes. After labeling with CD14-Phycoerythrin (PE) conjugated and CD16 Phycoerythrin cyanine-5 (PE-Cy5) conjugated monoclonal antibodies, monocytes can be separated into three distinct subsets, $\mathrm{CD} 14^{++} \mathrm{CD} 16^{-}$(upper left quadrant), $\mathrm{CD} 14^{++} \mathrm{CD} 16^{+}$(upper right quadrant) and $\mathrm{CD} 14^{+} \mathrm{CD}_{16}{ }^{+}$(lower right quadrant).

\section{1. $\mathrm{CD} 14^{++} \mathrm{CD}^{+} 6^{+}$subset concentrations in the two study groups}

The percentage of $\mathrm{CD} 14^{++} \mathrm{CD} 16^{+}$subset levels differed significantly between CHF patients and Controls. Median values of $\mathrm{CD} 14^{++} \mathrm{CD} 16^{+}$subset levels in $\mathrm{CHF}$ patients were 12.3 (first and third quartile, 8.7 and 14.8), while they were 5.9 (4.7-6.9) in Controls (Table 2). Monocyte count did not differ between smokers and non-smokers, diabetic and non-diabetic patients, or between those with or without a personal history of high blood pressure or with hypercholesterolemia. Similar- ly, no differences for $\mathrm{CD} 14^{++} \mathrm{CD} 16^{+}$subset concentrations were found when CHF patients were stratified according to whether they had ischemic (11.5, 8.4 and 14.8) or non-ischemic (12.5, 10.2 and 13.7) CHF.

\section{2. $\mathrm{CD} 14^{++} \mathrm{CD}^{+} 6^{+}$subset concentration and neurohormonal and functional measurements of heart failure severity}

Monocyte $\mathrm{CD} 14^{++} \mathrm{CD} 16^{+}$subset levels in CHF patients increased depending on how advanced the NYHA functional class was, (Fig. 3A) on worsening left 
Table 2

Laboratory tests of the study subjects

\begin{tabular}{|c|c|c|c|}
\hline & CHF patients (30) & Controls (26) & $\mathrm{p}$ \\
\hline $\mathrm{CD} 14^{++} \mathrm{CD} 16^{+}(\%)$ & $12.3(8.7-14.8)$ & $5.9(4.7-6.9)$ & $<0.05$ \\
\hline $\mathrm{CD}{ }^{+} \mathrm{CD} 16^{+}(\%)$ & $4.6(3.4-7.7)$ & $7.6(6.6-9.1)$ & $<0.05$ \\
\hline $\mathrm{sCD} 146(\mathrm{ng} / \mathrm{ml})$ & $672 \pm 91$ & $453 \pm 47$ & $<0.05$ \\
\hline Uric acid $\left(\mathrm{mg} \mathrm{dL}^{-1}\right)$ & $6.8 \pm 0.5$ & $6.12 \pm 0.2$ & NS \\
\hline Sodium $\left(\mathrm{mEq} \mathrm{L}^{-1}\right)$ & $142.0 \pm 0.6$ & $141.5 \pm 0.5$ & NS \\
\hline Potassium $\left(\mathrm{mEq} \mathrm{L}^{-1}\right)$ & $4.2 \pm 0.1$ & $4.0 \pm 0.1$ & NS \\
\hline Creatinine $\left(\mathrm{mg} \mathrm{dL}^{-1}\right)$ & $1.4 \pm 0.1$ & $1.1 \pm 0.1$ & $<0.05$ \\
\hline Total protein $\left(\mathrm{g} \mathrm{dL}^{-1}\right)$ & $7.2 \pm 0.2$ & $7.5 \pm 0.1$ & NS \\
\hline Serum fibrinogen $\left(\mathrm{mg} \mathrm{dL}^{-1}\right)$ & $452(358-494)$ & $369(301-434)$ & $<0.05$ \\
\hline C-reactive protein $\left(\mathrm{mg} \mathrm{L}^{-1}\right)$ & $15.1 \pm 3.6$ & $6.5 \pm 1.5$ & $<0.05$ \\
\hline White blood cell count $\left(\mathrm{mm}^{-3}\right)$ & $8339 \pm 619$ & $6492 \pm 256$ & $<0.05$ \\
\hline Neutrophil count $\left(\mathrm{mm}^{-3}\right)$ & $5855 \pm 542$ & $4119 \pm 227$ & $<0.05$ \\
\hline Monocyte count $\left(\mathrm{mm}^{-3}\right)$ & $629 \pm 61$ & $509 \pm 34$ & NS \\
\hline Pro-BNP (pg/ml) & $8431 \pm 2185$ & $115 \pm 48$ & $<0.05$ \\
\hline Serum albumin $(\mathrm{g} / \mathrm{L})$ & $3.6 \pm 0.1$ & $4.3 \pm 0.1$ & $<0.05$ \\
\hline
\end{tabular}

Values are expressed as mean $( \pm \mathrm{SE})$, median $(\mathrm{IQ})$, or as percentage. $\mathrm{CHF}=$ Congestive Heart Failure.

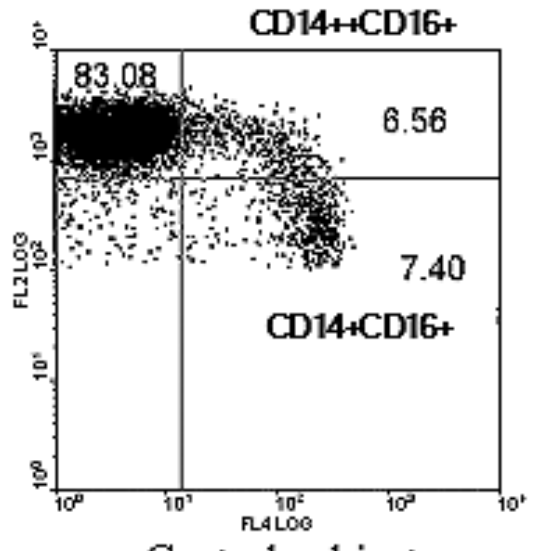

Control subject

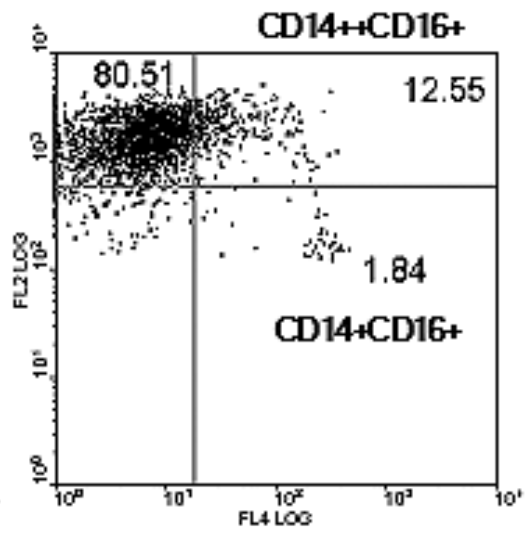

Mild HF

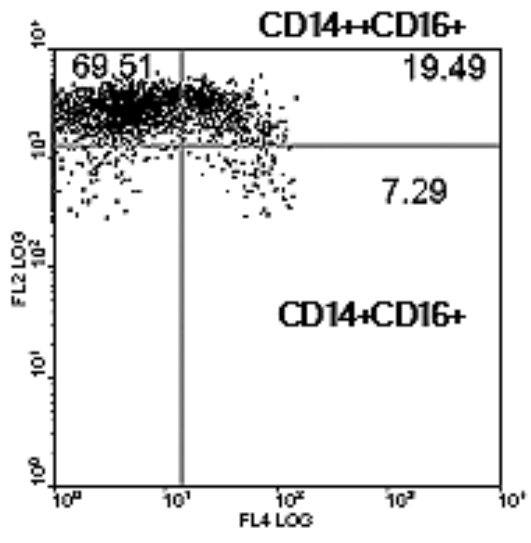

Severe HF

Fig. 2. Representative flow cytometric dot plots showing monocyte subsets from a healthy control and from two patients with increasing degrees of CHF severity.

ventricle ejection fraction (Fig. 3B), and on circulating pro-BNP values $(r=0.534$, p: 0.047; Spearman's rank correlation test), thus reflecting the relationship between this monocyte subset and HF severity.

\section{3. $\mathrm{CD} 4^{++} \mathrm{CD}^{+} 6^{+}$subset concentration and renal damage}

Monocyte $\mathrm{CD} 14^{++} \mathrm{CD} 16^{+}$subset levels were associated with increasing values of creatinine and with decreasing GFR and albumin levels. (Table 3) No relationships were observed between increasing age, reduced $\mathrm{Hb}$ levels or reduced BMI (range of BMI values: 20.2-29.1) and higher $\mathrm{CD} 14^{++} \mathrm{CD} 16^{+}$subset levels when $\mathrm{CD} 14^{++} \mathrm{CD} 16^{+}$levels were examined as a continuous variable, indicating that no significant association exists between age, Hb levels, BMI and CD14 ${ }^{++}$CD16 ${ }^{+}$levels. Furthermore, no relationships were found between the decrement in GFR and the following other acute-phase markers of inflammation: CRP, fibrinogen, WBC and neutrophil count.

\subsection{Correlation between the $\mathrm{CD} 14^{++} \mathrm{CDI}^{+}$subset and other markers}

CD14 ${ }^{++}$CD16 ${ }^{+}$subset levels were positively correlated with $\mathrm{CRP}$, which reflects increased systemic inflammation; likewise, $\mathrm{CD} 14^{++} \mathrm{CD} 16^{+}$subset levels were also positively correlated with neutrophil count. ACE/ARB inhibitors, lipid lowering drugs and betablockers are known to possess anti-inflammatory effects. Nonetheless, we observed no differences in the 
Table 3

Spearman's correlation coefficients showing relationships between monocytic CD14 ${ }^{+}{ }^{+} \mathrm{CD} 16^{+}$levels, $\mathrm{CD} 14^{+} \mathrm{CD} 16^{+}$levels, $\mathrm{CD} 143$ expression and laboratory variables

\begin{tabular}{|c|c|c|c|c|c|c|c|c|c|c|c|}
\hline & $\mathrm{CD}_{14}{ }^{++} \mathrm{CD} 16^{+}$ & $\mathrm{CD}_{14}{ }^{+} \mathrm{CD} 16^{+}$ & CD143 & SolCD146 & $\mathrm{EF}$ & Pro-BNP & Neutro.count & Creatinine & GFR & albumin & $\overline{C-R P}$ \\
\hline $\mathrm{CD}_{14}{ }^{++} \mathrm{CD} 16^{+}$ & - & $\begin{array}{c}0.072 \\
(0.726)\end{array}$ & $\begin{array}{c}0.553 \\
(0.042)\end{array}$ & $\begin{array}{c}0.113 \\
(0.577)\end{array}$ & $\begin{array}{c}0.628 \\
(0.022)\end{array}$ & $\begin{array}{c}0.534 \\
(0.047)\end{array}$ & $\begin{array}{c}0.522 \\
(0.049)\end{array}$ & $\begin{array}{c}0.544 \\
(0.046)\end{array}$ & $\begin{array}{c}0.558 \\
(0.040)\end{array}$ & $\begin{array}{c}0.590 \\
(0.038)\end{array}$ & $\begin{array}{c}0.656 \\
(0.019)\end{array}$ \\
\hline $\mathrm{CD}_{14}{ }^{+} \mathrm{CD} 16^{+}$ & - & - & $\begin{array}{c}0.442 \\
(0.083)\end{array}$ & $\begin{array}{c}0.529 \\
(0.048)\end{array}$ & $\begin{array}{c}0.274 \\
(0.189)\end{array}$ & $\begin{array}{c}0.385 \\
(0.123)\end{array}$ & $\begin{array}{c}0.031 \\
(0.887)\end{array}$ & $\begin{array}{c}0.112 \\
(0.575)\end{array}$ & $\begin{array}{c}0.181 \\
(0.374)\end{array}$ & $\begin{array}{c}0.131 \\
(0.534)\end{array}$ & $\begin{array}{c}0.077 \\
(0.788)\end{array}$ \\
\hline CD143 & - & - & - & $\begin{array}{c}0.129 \\
(0.522)\end{array}$ & $\begin{array}{c}0.326 \\
(0.166)\end{array}$ & $\begin{array}{c}0.134 \\
(0.511)\end{array}$ & $\begin{array}{c}0.230 \\
(0.291)\end{array}$ & $\begin{array}{c}0.057 \\
(0.783)\end{array}$ & $\begin{array}{c}0.142 \\
(0.480)\end{array}$ & $\begin{array}{c}0.179 \\
(0.392)\end{array}$ & $\begin{array}{c}0.254 \\
(0.250)\end{array}$ \\
\hline
\end{tabular}
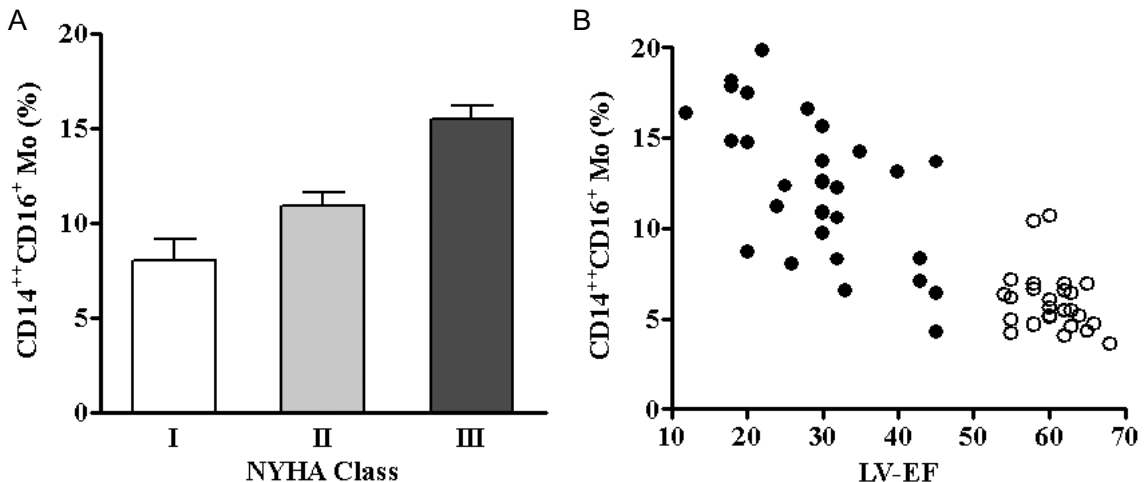

Fig. 3. Relationships of $\mathrm{CD} 14^{++} \mathrm{CD} 16^{+}$monocyte frequencies with parameters of $\mathrm{CHF}$ severity; A) Relationship between $\mathrm{CD} 14^{++} \mathrm{CD} 16^{+}$ monocyte frequencies and Functional Severity in CHF patients. Results were stratified by the severity of heart failure expressed by New York Heart Association (NYHA) functional class, and were compared by the Kruskal-Wallis one-way analysis of variance $(p=0.0002)$. B) Relationship between $\mathrm{CD} 14^{+}{ }^{+} \mathrm{CD}_{16}{ }^{+}$monocyte frequencies and left ventricular ejection fraction (LV-EF) in CHF patients (solid circles) and in Control subjects (open circles). Results were compared by non parametric Spearman's rank correlation test $(r=-0.628$; $\mathrm{p} 0.022$ for CHF patients; $r=$ -0.245 ; p 0.439 for Control subjects).

$\mathrm{CD} 14^{++} \mathrm{CD} 16^{+}$subset levels in $\mathrm{CHF}$ patients, regardless of whether they were taking these drugs or not.

\subsection{Monocyte CD143 (ACE) surface expression}

Monocyte CD143 expression was significantly elevated in CHF patients as compared to Control subjects (Fig. 4A; $p<0.05$, Mann Whitney) . Among the various monocyte subsets, $\mathrm{CD} 14^{++} \mathrm{CD} 16^{+}$monocytes showed the highest CD143 expression (Fig. 4B). Monocyte $\mathrm{CD} 14^{++} \mathrm{CD} 16^{+}$levels and ACE expression had a significant, positive relationship within the group of CHF patients and within the whole cohort $(r=$ 0.553, p: 0.042 , and $r=0.469$, p:0.006; Spearman's rank correlation test); the Control group failed to show this correlation, suggesting that the result in the whole cohort reflected the contribution of CHF patients. NYHA class and HF aetiology were not associated with different values of monocyte CD143 expression (data not shown). Use of ACE inhibitors, $\beta$-blockers, aspirin analysed in the whole cohort (and then separately in CHF patients and in Control subjects), and use of digoxin, loop diuretics, spironolactone and angiotensin receptor blocker analysed in $\mathrm{CHF}$ patients did not affect monocyte ACE expression.

\section{6. $\mathrm{CDI}^{+} \mathrm{CD}^{+} 6^{+}$subset concentration and endothelial damage}

Frequencies of $\mathrm{CD} 14^{+} \mathrm{CD} 16^{+}$monocytes were significantly lower in $\mathrm{CHF}$ patients as compared to Controls $(p<0.05)$ (Table 2). CD14 ${ }^{+} \mathrm{CD} 16^{+}$subset levels in CHF patients showed a median value of 4.6 (first and third quartile, 3.4 and 7.7), as compared to a median value of 7.6 (first and third quartile, 6.6 and 9.1) in Controls. sCD146 levels, which reflect endothelial damage, were significantly increased in $\mathrm{CHF}$ patients compared to control subjects (mean values and SE: $672 \pm 91$ vs. $453 \pm 47 \mathrm{ng} / \mathrm{ml} ; p<0.05$ ) (Table 2). Patients with CHF due to ischemic heart disease and to idiopathic dilated cardiomyopathy did not differ as far as sCD146 levels were concerned (565.9 $\pm 135 \mathrm{ng} / \mathrm{ml}$ vs $687.2 \pm 108 \mathrm{ng} / \mathrm{ml}$, respectively; $p<$ NS); similarly, sCD146 levels were not related to NY$\mathrm{HA}$ class or to $\mathrm{EF}$ in $\mathrm{CHF}$ patients. Moreover, plasma sCD146 concentrations showed a negative correlation 
A

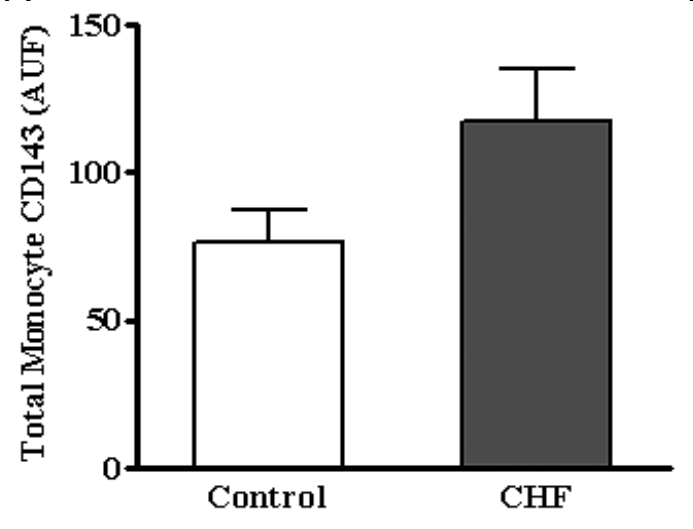

B

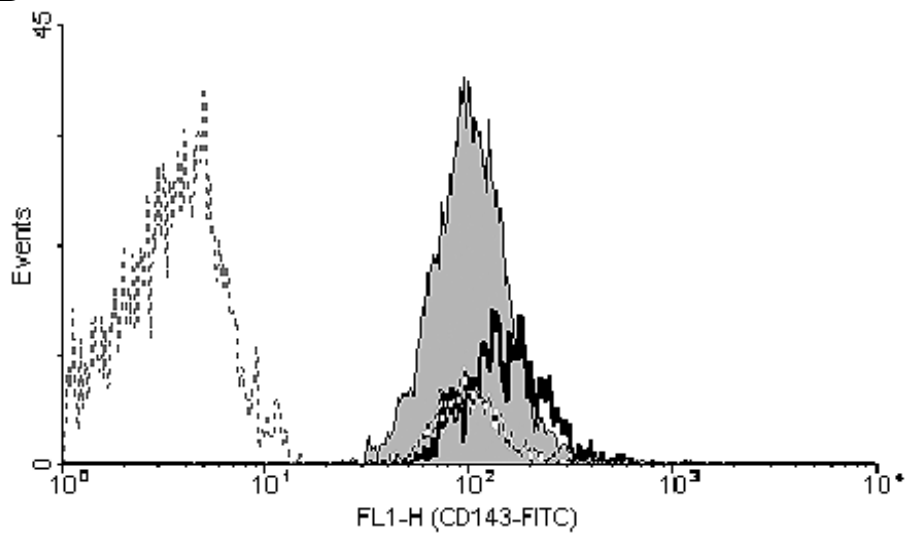

Fig. 4. Monocyte surface expression of CD143 (ACE); A) monocytic CD143 levels in control subjects and in CHF patients. Results were compared by the Mann Whitney test $(p<0.05$, CHF Patients vs Control). B) Representative flow cytometric histograms depicting monocyte surface CD143-FITC fluorescence on different monocyte subsets as analyzed by three-color immunofluorescence within $\mathrm{CD}^{-{ }^{+}}{ }^{+} \mathrm{CD} 16^{-}($filled histogram), $\mathrm{CD} 14^{++} \mathrm{CD}^{+} 6^{+}$(thick solid line) and $\mathrm{CD} 14^{+} \mathrm{CD} 16^{+}$(dotted black line) monocyte subsets; dotted gray line histogram represents isotype control staining.

with $\mathrm{CD} 14^{+} \mathrm{CD} 16^{+}$monocyte subset frequencies $(r=$ -0.529 ; p 0.048; Spearman's rank correlation test).

\section{Discussion}

Monocytes have been implicated in mechanisms of progression of atherosclerotic damage in experimental models and in human pathologies $[16,17]$. In this study, we report that the monocyte $\mathrm{CD} 14^{++} \mathrm{CD} 16^{+}$subset is differently expanded in our CHF population as compared to Control subjects; CD14 ${ }^{++} \mathrm{CD} 16^{+}$levels increased depending on CHF disease severity and were associated with renal damage, as well as with monocyte ACE expression, neutrophil count and with circulating levels of CRP in our CHF patients. Lastly, we showed that the $\mathrm{CD} 14^{+} \mathrm{CD} 16^{+}$levels were decreased in $\mathrm{CHF}$ patients and were linked to endothelial damage.

\section{1. $\mathrm{CDI}^{++} \mathrm{CD}^{+} 6^{+}$monocyte frequencies in $\mathrm{CHF}$ patients}

Peripheral monocyte heterogeneity is widely acknowledged [18]. While most of the monocytes in healthy individuals are $\mathrm{CD}_{16}^{-}$, a minor subset of monocytes is made up of $\mathrm{CD}_{16}{ }^{+}$monocytes. $\mathrm{CD}^{+} 6^{+}$ monocytes show characteristics of tissue macrophages, and may further be divided into $\mathrm{CD}_{14}{ }^{+}$(dim or low) and $\mathrm{CD}_{14}^{++}$(high), depending on the differential expression of CD14. The $\mathrm{CD} 14^{++} \mathrm{CD} 16^{+}$subset was initially tagged as a pro-inflammatory subset, [19,
20] but recently Skrzeczynska-Moncznik demonstrated that the pro-inflammatory signature associated with the $\mathrm{CD} 14^{++} \mathrm{CD} 16^{+}$subset was not always in favor of increased cytokine production, but rather that it displayed mixed findings [5]. The number of circulating $\mathrm{CD} 14^{++} \mathrm{CD}_{16}{ }^{+}$increases in several inflammatory conditions [21]. An initial report on patients with ischemic heart disease was consistent with more elevated monocyte $\mathrm{CD} 14^{++} \mathrm{CD} 16^{+}$subset levels in these patients when compared to age matched, healthy subjects [22]. Foldes recently demonstrated differences in the unstimulated monocytic expression of CD14 and in the pro-inflammatory receptor toll-like receptor 4 (TLR-4), in that both were more highly expressed in failing hearts than in normal hearts [23]. Multiple pathophysiological mechanisms and factors have been implicated in initiating and mediating the progressive deterioration of contractile function during heart failure [24]. Thus, clarifying whether CD14 ${ }^{++}$CD16 ${ }^{+}$ monocytes play a role in the progression of heart failure would appear to be of great importance since the link between inflammation and heart failure is gaining acceptance [3]. Small changes in the surface expression of $\mathrm{CD} 14^{++} \mathrm{CD} 16^{+}$may in fact impact on the intracellular inflammatory signaling pathways and on immune surveillance in CHF patients. Our results are consistent with an increase in the monocyte $\mathrm{CD} 14^{++} \mathrm{CD}^{+} 6^{+}$subset in CHF patients. Moreover, monocyte $\mathrm{CD} 14^{++} \mathrm{CD} 16^{+}$subset appears to be incrementally recruited at different stages of HF severity. Monocyte $\mathrm{CD} 14^{++} \mathrm{CD} 16^{+}$may provoke damage by 
infiltrating the failing myocardium and by contributing to the systemic inflammatory processes.

\section{2. $\mathrm{CDI}^{++} \mathrm{CD}^{+} 6^{+}$Relationship with monocyte ACE expression, renal damage, CRP levels, neutrophil count}

Indexes of renal function were correlated to monocyte $\mathrm{CD} 14^{++} \mathrm{CD} 16^{+}$levels. Accordingly, some parameters which reflect decreased renal function (renal clearance, hypoalbuminemia) or are associated (ACE expression) with it predicted increased CD14 ${ }^{++}$ $\mathrm{CD}_{16}{ }^{+}$levels. The present study extends the finding of increased monocytic ACE expression in dialysis patients with prevalent cardiovascular disease [8]. The finding that the $\mathrm{CD} 14^{++} \mathrm{CD} 16^{+}$subset, which is expanded in CHF patients, also expresses a monocyte Angiotensin II generating system, provides evidence that in addition to hemodynamic and tissue effects, activation of the renin-angiotensin system in HF patients promotes a systemic inflammatory response. It is noteworthy that, as already shown by Ulrich et al. the use of ACE-inhibitors, AT-1 inhibitors, and of spironolactone in our patients did not affect monocytic ACE expression [8]. Reduced renal clearance, hypoalbuminemia, and increased ACE expression all fit with the chronic inflammatory activation pattern previously reported in patients with severe renal dysfunction. Our study groups included a sizeable number of CHF patients whose GFR led to classification as stage 2 or 3 CKD. We decided to include these patients because the prevalence of stage 2 or 3 CKD in the general CHF population is fairly high. Thus, a potential explanation for our findings can be derived from the link between increased monocyte $\mathrm{CD} 14^{++} \mathrm{CD} 16^{+}$levels and mild-to-moderate renal dysfunction in CHF patients. Finally, circulating levels of CRP and neutrophil count were also linked to monocyte $\mathrm{CD} 14^{++} \mathrm{CD} 16^{+}$ levels, but not to GFR. High levels of CRP and of neutrophils have already been described in CHF patients, and we may assume that monocyte $\mathrm{CD} 14^{++} \mathrm{CD} 16^{+}$ expand in response to this inflammatory milieu. Levels of Myeloperoxidase (MPO), which is a product of activated neutrophils, are in excess in CHF patients. Tang reported that MPO levels were linked to functional and neurohormonal indexes of worsening heart failure, similarly to what we observed for monocyte CD14 ${ }^{++}$CD16 ${ }^{+}$levels [25]. Therefore, it is not surprising that activated neutrophils and pro-inflammatory monocyte subsets may reciprocally act as enhancers of the pro-inflammatory cycle in this disease setting.

\section{3. $\mathrm{CDI}^{+} \mathrm{CD}^{+} 6^{+}$monocyte frequencies in $\mathrm{CHF}$ patients}

$\mathrm{CD} 14^{+} \mathrm{CD} 16^{+}$subset frequencies were decreased in $\mathrm{CHF}$ patients. This observation is in line with the finding by Ancuta et al. who showed that $\mathrm{CD}_{16}{ }^{+}$and $\mathrm{CD}^{-} 6^{-}$monocytes have distinct patterns of chemotactic migration: $\mathrm{CD}_{16}{ }^{+}$monocytes preferentially adhere to stimulated endothelial cells and undergo efficient transendothelial migration in response to the fractalkine pathway [26]. Ancuta found that CD16 ${ }^{+}$ monocytes expressed high CX3CR1 levels, and in particular that the $\mathrm{CD} 14^{+} \mathrm{CD} 16^{+}$monocyte subset expressed the highest CX3CR1 levels. The increase in soluble CD146 levels, which represent a marker of endothelial junctional alterations [27] in our CHF patients, together with the negative correlation between sCD146 levels and CD14 ${ }^{+} \mathrm{CD} 16^{+}$monocyte subset frequency, suggests a link between low $\mathrm{CD} 14^{+} \mathrm{CD} 16^{+}$ monocyte frequencies and endothelial damage in this group of patients. Endothelial dysfunction and damage have been described in CHF. Therefore, we believe that the decrease in $\mathrm{CD} 14^{+} \mathrm{CD} 16^{+}$monocytes in our $\mathrm{CHF}$ patients may reflect their preferential recruitment at the level of damaged endothelium.

Reduced CD14 ${ }^{+} \mathrm{CD} 16^{+}$levels in $\mathrm{CHF}$ patients suggest that $\mathrm{CD} 14^{+} \mathrm{CD} 16^{+}$monocytes may represent a new target for the modulation of the endothelial damage that is present in this group of patients.

Our observational study cannot be used to make causal inferences, and doubts remain about the biological significance of increased $\mathrm{CD} 14^{++} \mathrm{CD} 16^{+}$levels in this setting of patients. If $\mathrm{CD} 14^{++} \mathrm{CD} 16^{+}$monocytes are truly drivers of inflammation, then agents that inhibit the expansion or the action of this monocyte subset may prevent or reverse myocardial dysfunction and cardiac remodeling, or limit extracardiac damage in $\mathrm{CHF}$ patients. On the contrary, if $\mathrm{CD} 14^{++} \mathrm{CD} 16^{+}$ levels simply represent indicators of the extent of inflammation, it would be important to ascertain whether they can be used as outcome predictors.

As suggested by Sundstrom in relation to the clinical application of new circulating biomarkers, the road leading new circulating biomarkers (such as monocyte CD14CD16 subset levels) from bench to bedside is still long because their immediate clinical usefulness may be limited [28]. Nonetheless, although it remains unclear whether differences in monocyte CD14CD16 expansion are causal or whether their measurements can be relevant only for risk prediction in $\mathrm{CHF}$, we believe that they represent a new and important tool that can be used to explore the role of selective inflammatory pathways in the progression of $\mathrm{CHF}$. 


\subsection{Study limitations}

Modulation of monocyte activity requires a careful approach because monocyte phenotypes possess distinct mechanisms for tissue-specific recruitment [27]. Interpretation of the present results is limited by the small number of patients we studied. However, the correlations we found may serve as a reliable marker in the evaluation of $\mathrm{CHF}$ severity.

\section{Conclusions}

Clinical implications.

For the first time we have shown that monocyte $\mathrm{CD} 14^{++} \mathrm{CD} 16^{+}$levels were raised and had an enhanced ACE expression in CHF patients. Furthermore, monocyte $\mathrm{CD} 14^{++} \mathrm{CD} 16^{+}$levels were linked to poor cardiac functional class, reduced renal function, and high CRP levels. In addition, the monocyte $\mathrm{CD} 14^{+} \mathrm{CD} 16^{+}$subset was depleted in CHF, and was linked to endothelial damage in this group of patients. How to use this information at the moment remains to be clarified, but it is reasonable to hypothesize that selective modulation of monocyte CD14CD16 expansion is likely to be relevant for the progression of $\mathrm{CHF}$.

\section{Acknowledgments}

The Authors would like to thank Valerie Frances Perricone for editorial assistance.

\section{References}

[1] H.J. Dargie and J.J. McMurray, Diagnosis and management of heart Failure, BMJ 308 (1994), 321-328.

[2] R.T. Tsuyuki, M.C. Shibata, C. Nilsson and M. Hervas-Malo, Contemporary burden of illness of congestive heart failure in Canada, Can J Cardiol 19 (2003), 436-438.

[3] S. Heymans, E. Hirsch, S.D. Anker, P. Aukrust, J.L. Balligand, J.W. Cohen-Tervaert, H. Drexler, G. Filippatos, S.B. Felix, L. Gullestad, D. Hilfiker-Kleiner, S. Janssens, R. Latini, G. Neubauer, W.J. Paulus, B. Pieske, P. Ponikowski, B. Schroen, H.P. Schultheiss, C. Tschöpe, M. Van Bilsen, F. Zannad, J. McMurray and A.M. Shah, Inflammation as a therapeutic target in heart failure? A scientific statement from the Translational Research Committee of the Heart Failure Association of the European Society of Cardiology, Eur J Heart Fail 11 (2009), 119-129.

[4] W.A. Nockher, J. Wiemer and J.E. Scherberich, Haemodialysis monocytopenia: differential sequestration kinetics of $\mathrm{CD}{ }^{+} \mathrm{CD} 16^{+}$and $\mathrm{CD} 14^{++}$blood monocyte subsets, Clin Exp Immunol 123 (2001), 49-55.
[5] J. Skrzeczyńska-Moncznik, M. Bzowska, S. Loseke, E. GrageGriebenow, M. Zembala and J. Pryjma, Peripheral blood CD14high CD16 ${ }^{+}$monocytes are main producers of IL-10, Scand J Immunol 67 (2008), 152-159.

[6] V.J. Dzau, K. Bernstein, D. Celermajer, J. Cohen and M. Weber, Pathophysiologic and therapeutic importance of tissue ACE: a consensus report, Cardiovasc Drugs Ther 16 (2002), 149-160.

[7] S.M. Danilov, E. Sadovnikova, N. Scharenborg, I.V. Balyasnikova, D.A. Svinareva, E.L. Semikina, E.N. Parovichnikova, V.G. Savchenko and G.J. Adema, Angiotensin-converting enzyme (CD143) is abundantly expressed by dendritic cells and discriminates human monocyte-derived dendritic cells from acute myeloid leukemia-derived dendritic cells, Exp Hematol 31 (2003), 1301-1309.

[8] C. Ulrich, G.H. Heine, P. Garcia, B. Reichart, T. Georg, M. Krause, H. Köhler and M. Girndt, Increased expression of monocytic angiotensin-converting enzyme in dialysis patients with cardiovascular disease, Nephrol Dial Transplant 21 (2006), 1596-1602.

[9] N. Kawanaka, M. Yamamura, T. Aita, Y Morita, A. Okamoto, M. Kawashima, M. Iwahashi, A. Ueno, Y. Ohmoto and H. Makino, $\mathrm{CD}_{14}{ }^{+}, \mathrm{CD}_{16}{ }^{+}$blood monocytes and joint inflammation in rheumatoid arthritis, Arthritis Rheum 46 (2002), 2578-2586.

[10] H. Hanai, T. Iida, K. Takeuchi, F. Watanabe, M. Yamada, M. Kikuyama, Y. Maruyama, Y. Iwaoka, K. Hirayama, S. Nagata and K. Takai, Adsorptive depletion of elevated proinflammatory $\mathrm{CD} 14^{+} \mathrm{CD}_{16}{ }^{+} \mathrm{DR}^{++}$monocytes in patients with inflammatory bowel disease, Am J Gastroenterol 103 (2008), 1210-1216.

[11] M. Moniuszko, A. Bodzenta-Lukaszyk, K. Kowal, D. Lenczewska and M. Dabrowska, Enhanced frequencies of $\mathrm{CD} 14^{++} \mathrm{CD}^{+} 6^{+}$, but not $\mathrm{CD} 14^{+} \mathrm{CD} 16^{+}$, peripheral blood monocytes in severe asthmatic patients, Clin Immunol 130 (2009), 338-346.

[12] S.D. Anker, K.R. Egerer, H.D. Volk, W.J. Kox, P.A. PooleWilson and A.J. Coats, Elevated soluble CD14 receptors and altered cytokines in chronic heart failure, Am J Cardiol 79 (1997), 1426-1430.

[13] P.A. McKee, W.P. Castelli, P.M. McNamara and W.B. Kannel, The natural history of congestive heart failure: the Framingham study, N Engl J Med 285 (1971), 1441-1446.

[14] A.S. Levey, J.P. Bosch, J.B. Lewis, T. Greene, N. Rogers and D. Roth, Modification of Diet in Renal Disease Study Group. A more accurate method to estimate glomerular filtration rate from serum creatinine: a new prediction equation, Ann Intern Med 130 (1999), 461-470.

[15] P. de Groote, R Isnard, P. Clerson, G. Jondeau, M. Galinier, P. Assyag, N. Demil, A. Ducardonnet, J.F. Thebaut and M. Komajda, Improvement in the management of chronic heart failure since the publication of the updated guidelines of the European Society of Cardiology. The Impact-Reco Programme, Eur J Heart Fail 11 (2009), 85-91.

[16] J. Mestas and K. Ley, Monocyte-endothelial cell interactions in the development of atherosclerosis, Trends Cardiovasc Med 18 (2008), 228-232.

[17] H.W. Ziegler-Heitbrock, Heterogeneity of human blood monocytes: the CD14 ${ }^{+} \mathrm{CD}^{+} 6^{+}$subpopulation, Immunol Today $\mathbf{1 7}$ (1996), 424-428.

[18] S. Gordon and P.R. Taylor, Monocyte and macrophage heterogeneity, Nat Rev Immunol 5 (2005), 953-964.

[19] K.U. Belge, F. Dayyani, A. Horelt, M. Siedlar, M. Frankenberger, B. Frankenberger, T. Espevik and L. Ziegler-Heitbrock, 
The proinflammatory $\mathrm{CD} 14^{+} \mathrm{CD} 16^{+} \mathrm{DR}^{++}$monocytes are a major source of TNF, J Immunol 168 (2002), 3536-3542.

[20] C. Weber, K.U. Belge, P. von Hundelshausen, G. Draude, B. Steppich, M. Mack, M. Frankenberger, K.S. Weber and H.W. Ziegler-Heitbrock, Differential chemokine receptor expression and function in human monocyte subpopulations, $J$ Leukoc Biol 67 (2000), 699-704.

[21] J.E. Scherberich and W.A. Nockher, CD14 ${ }^{++}$monocytes, $\mathrm{CD} 14^{+} / \mathrm{CD} 16^{+}$subset and soluble CD14 as biological markers of inflammatory systemic diseases and monitoring immunosuppressive therapy, Clin Chem Lab Med 37 (1999), 209-213.

[22] A. Schlitt, G.H. Heine, S. Blankenberg, C. Espinola-Klein, J.F. Dopheide, C. Bickel, K.J. Lackner, M. Iz, J. Meyer, H. Darius and H.J. Rupprecht, CD14 ${ }^{+} \mathrm{CD} 16^{+}$monocytes in coronary artery disease and their relationship to serum TNF-alpha levels, Thromb Haemost 92 (2004), 419-424.

[23] G. Földes, S. von Haehling, D.O. Okonko, E.A. Jankowska, P.A. Poole-Wilson and S.D. Anker, Fluvastatin reduces increased blood monocyte Toll-like receptor 4 expression in whole blood from patients with chronic heart failure, Int $J$ Cardiol 124 (2008), 80-85.

[24] E. Braunwald, The Denolin lecture. Congestive heart failure: a half century perspective, Eur Heart J 22 (2001), 825-836.

[25] W.H. Tang, M.L. Brennan, K. Philip, W. Tong, S. Mann, F. Van Lente and S.L. Hazen, Plasma myeloperoxidase levels in patients with chronic heart failure, Am J Cardiol 98 (2006), 796-799.

[26] P. Ancuta, R. Rao, A. Moses, A. Mehle, S.K. Shaw, F.W. Luscinskas and D. Gabuzda, Fractalkine preferentially mediates arrest and migration of $\mathrm{CD} 16^{+}$monocytes, J Exp Med 197 (2003), 1701-1707.

[27] N. Bardin, V. Moal, F. Anfosso, L. Daniel, P. Brunet, J. Sampol and G.F. Dignat, Soluble CD146, a novel endothelial marker, is increased in physiopathological settings linked to endothelial junctional alteration, Thromb Haemost 90 (2003), 915-920.

[28] J. Sundström, Myocardial biomarkers for prediction of cardiovascular disease, Dis Markers 26 (2009), 235-246. 


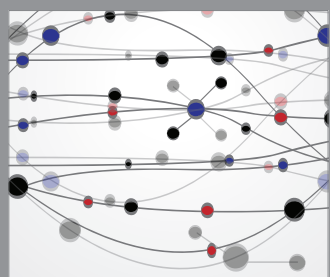

The Scientific World Journal
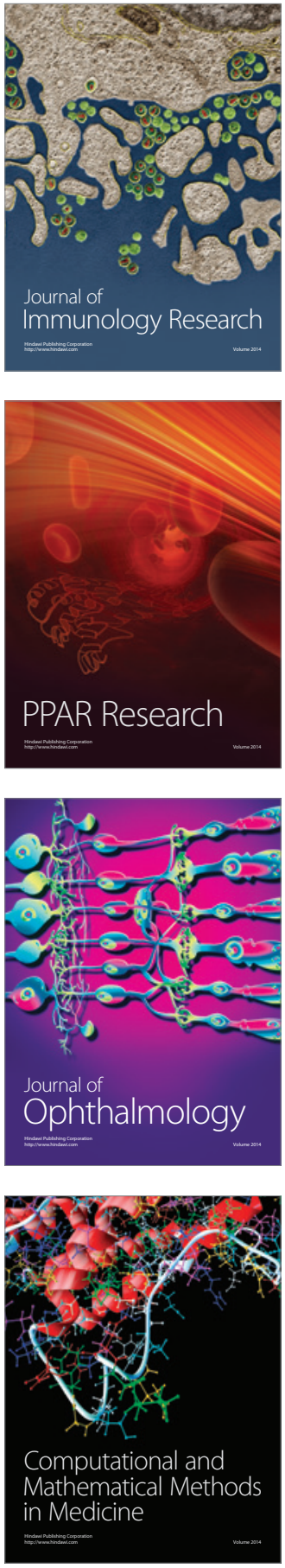

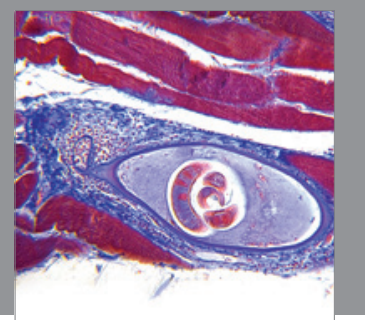

Gastroenterology

Research and Practice
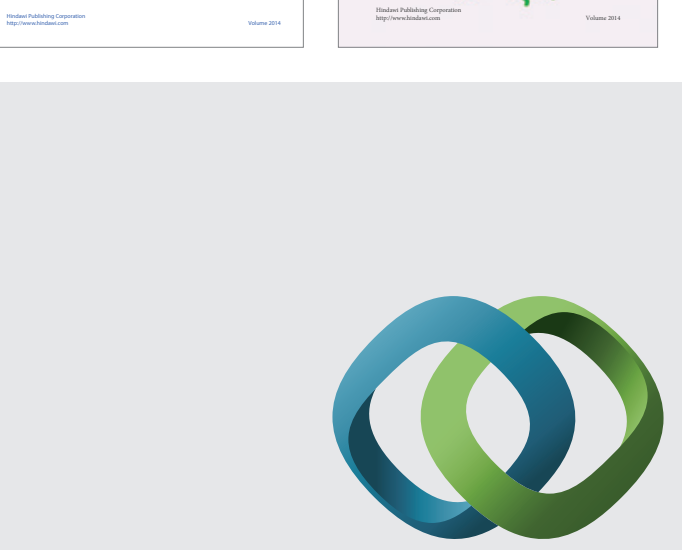

\section{Hindawi}

Submit your manuscripts at

http://www.hindawi.com
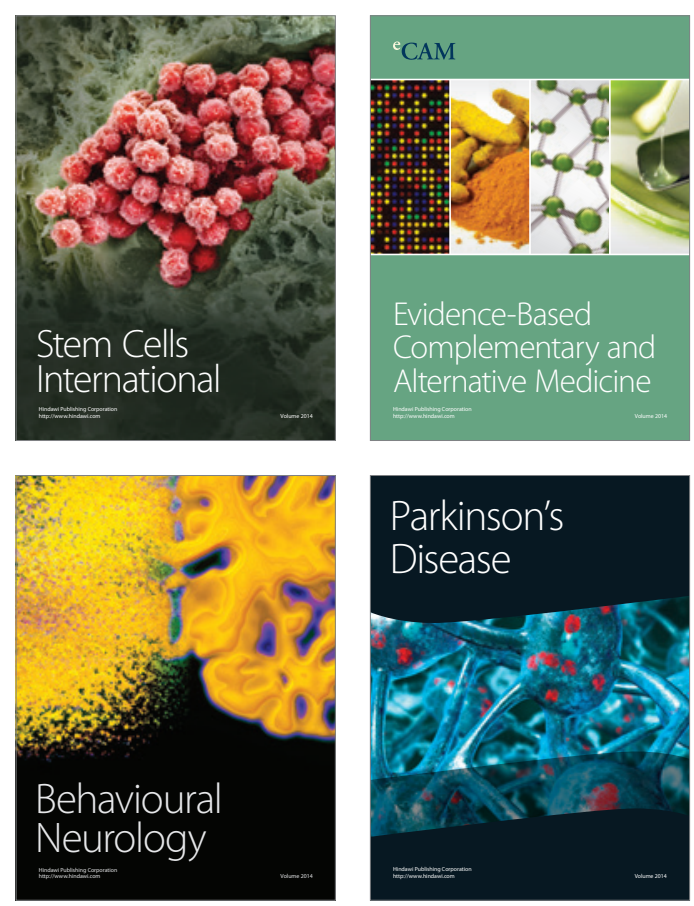

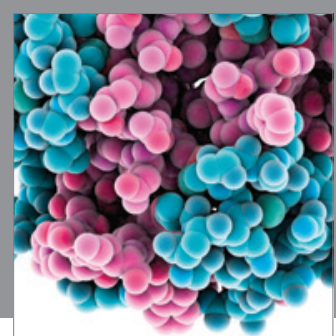

Journal of
Diabetes Research

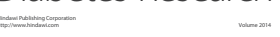

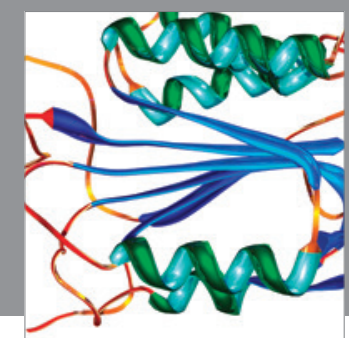

Disease Markers
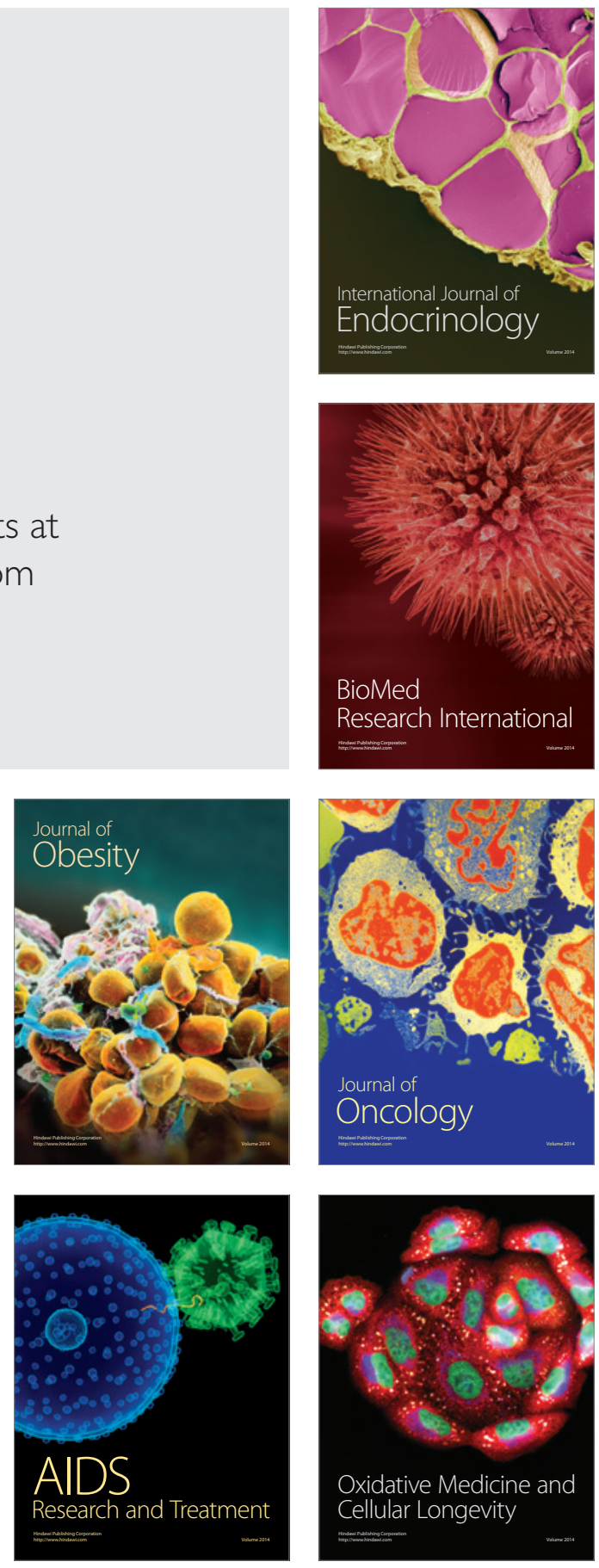